\title{
Support for assessment practice: developing the Assessment Design Decisions Framework
}

Margaret Bearman, Phillip Dawson, David Boud, Sue Bennett, Matt Hall and Elizabeth Molloy

\begin{abstract}
There are many excellent publications outlining features of assessment and feedback design in higher education. However, university educators often find these ideas challenging to realise in practice, as much of the literature focuses on institutional change rather than supporting academics. This paper describes the conceptual development of a practical framework designed to stimulate educators' thinking when creating or modifying assessments. We explain the concepts that underpin this practical support, including the notions of 'assessment decisions' and 'assessment design phases', as informed by relevant literature and empirical data. We also present the outcome of this work. The Assessment Design Decisions Framework. This provides key considerations in six categories: purposes, contexts, tasks, interactions, feedback processes and learning outcomes. By tracing the development of the Framework, we highlight complex ways of thinking about assessment that are relevant to those who design and deliver assessment to tertiary students.
\end{abstract}

\section{Introduction}

Assessment and feedback can be troublesome areas for university educators, but this is not through want of higher education scholarship. A range of conceptual and empirical publications informing assessment are readily available to most university teachers (e.g. Gore et al. 2009; Boud 2010; Van der Vleuten et al. 2012; Falchikov 2013). In general, the literature focuses more on the learner and their experience of assessment (e.g. Bailey and Garner 2010; Nicol 2010; Shipman et al. 2012) and less on the central role of the educator in designing, implementing and judging assessments. This creates a conundrum for those who wish to improve assessment: how to keep the focus on the learner while including the educator who holds the primary responsibility for assessment. This paper describes the conceptualisation and development of a learner-focused resource, which supports educators' agency in making considered, nuanced and effective assessment design choices. 
The need for such a resource is supported by a range of conceptual and empirical literature. Previous work highlights the organisational and policy challenges of supporting good assessment practice (Gibbs \& Dunbar-Goddet, 2007; Macdonald and Joughin 2009; Meyer et al. 2010; Price et al. 2011). In particular, Price et al. (2011) suggest the need to enhance the pedagogic and assessment literacy levels of both faculty and students.

Developing assessment literacy seems a reasonable aim, but on further inspection may only be one part of the solution. Studies into conceptions of assessment indicate the significant variation in how individual academics think about assessment (Fletcher et al. 2012) and how these conceptualisations can be at odds with what academics do (Norton, Norton, and Shannon 2013). Offerdahl and Tomanek (2011) describe how individuals' changed thinking about assessment may not lead to changed teaching practices. In this case study, three educators considered studentcentred strategies, such as using formative assessment that revealed information about students' progress to inform teaching. These strategies were implemented, but ultimately realigned to the previous didactic approach that focused on students' provision of correct 'answers'. Offerdahl and Tomanek (2011) speculate that a stronger degree of dissatisfaction with the status quo may be required to stimulate genuine change. Their study highlights three issues. First, it is more difficult to change assessment practices than it is to change theoretical understandings. Second, there are little data that reveal the reasons for educators' assessment choices. Finally, if institutions and departments wish to support individual educators to improve assessments, they must consider the influence of the many contextual factors which shape educator practice.

These complexities and tensions underlying assessment practice formed the driver for our multi-institutional project Improving assessment: understanding educational decision- making in practice. The purpose of this project was to develop supports for the design of assessments, which are to take into account the challenges of local contexts. This may be conceptualised as the challenge of supporting 'work-as-done', which is distinguished from supporting 'work-asimagined'. Braithwaite, Wears, and Hollnagel $(2015,419)$ note: 'work-asimagined always differs from what actually goes on - work-as-done'. In the context of higher education assessment, 'work-as-imagined' is well represented by institutional visions and policies, as well as the many excellent models and innovations within the assessment research literature. There is considerably less work which considers 'work-as-done', or the actual experience of assessment practice, and even less work again which supports 'front-line' educators to enhance their assessments. This is the gap that our project intended to address. 
This paper describes the conceptual approaches which underpin the development of these 'front-line' assessment design supports. First, we describe our perspectives on the role of assessment followed by an account how we came to define 'assessment design decisions'. Next, we document the progression of our thinking about how educators produce assessment, drawing from theory, published research, our own work as assessment practitioners and an empirical data-set collected as part of the project. We then outline the Assessment Design Decisions Framework, which is intended to support and motivate educators to produce and implement good assessment designs, without being prescriptive or reductive. This Framework stimulates educators to consider the tensions in assessment design, while acknowledging constraints and affordances of their particular contexts. Finally, we reflect on what may be important in supporting educators to design assessments and provide some directions for future research, including evaluating the Framework's impact.

The Assessment Design Decisions Framework is intended for the specific context of the Australian higher education environment. However, we deliberately took a broader approach. We drew from international literature to ensure that while our project reflected Australian disciplinary and institutional variation, it was also relevant to global contexts where assessment practices may be different.

\section{Perspectives on assessment}

An initial step for our project team was to document an explicit and reflexive shared understanding of what was significant about assessment. Then, as at present, we define university assessment as the graded and non-graded tasks, undertaken by an enrolled student as part of their formal study, where the learner's performance is judged by others (teachers or peers). Like Price et al. (2011), we hold the premise that, while assessment strategies should balance complex and interdependent purposes including accreditation and portrayal of achievements, assessment activities should focus on learning and discourage mechanical approaches to study. We also claim that assessment practices should develop learners' own capacities to evaluate their own work to prepare them for future challenges beyond the support of teachers and courses. Assessment necessarily directs learners' efforts to mastering the 'rules of the game', whether that be writing an essay, answering a multiple-choice question, or conducting an interview. It does so in ways that are not neutral; assessment always acts as an intervention into student learning. We hold that feedback processes are critical to effective learning through assessment (Nicol and Macfarlane-Dick 2006) and that iterative opportunities for learners to incorporate feedback is a key component of effective practice (Boud and Molloy 2013). These views, while contemporary, are uncontroversial and well represented in the literature. 


\section{Defining assessment design decisions}

There are few publications examining the processes educators undertake to optimally design and judge assessments in complex practice environments. As discussed earlier, studies indicate a gap between what educators conceptualise as good assessment practice and what they actually do (Offerdahl and Tomanek 2011; Norton, Norton, and Shannon 2013), however these studies offer only limited insight into why the educators ultimately failed tochange their practices. In his study of general teaching practice,Eley (2006)examined university educators' thinking when planning for teaching. He concluded that specific decisions stem from contextualised teaching repertoires, rather than abstract principles of 'good teaching'.

The notion of 'decision-making' for teachers in higher education resonates with other industries where practitioners have to make decisions that balance competing and multi- factorial demands. Although Eley (2006) does not reference it, there is a body of literature on 'decision-making' drawing primarily from cognitive traditions (Borko et al. 2008) in such industries as aviation (Plant and Stanton 2013) and healthcare (Croskerry 2005), as well as in teacher education (Borko et al. 2008). At the commencement of the project, we postulated that assessment practice, with the complexity of its competing tensions (Price et al. 2011) and contextual constraints (Macdonald and Joughin 2009) could likewise be understood as educators making a series of decisions.

Assessment decision-making is not an established construct in the literature. Our initial conceptualisation began by considering what actions are taken and by whom. We noted that different decisions about assessment occur at different points in the lifespan of a program, and different people make these decisions for different purposes. Some assessment decisions are made at a policy level (e.g. maximum weightings mandated for exams), often by senior staff, who may have no direct relationship with students and are independent of an actual course. Other assessment decisions are made during the design of the unit or module (e.g. types of task and criteria for success), usually by univer- sity teachers as individuals or in teams, who have some relationship or responsibility for the unit or overall course. We clustered these decisions into a 'design phase'. Finally, there is assessment in the form of day-to-day judgements of student work (e.g. types of feedback and grades given to a particular student), often made by assessors who may be tutors or colleagues without responsibility for the assessment design. All three types of decisions influence and are influenced by each other. However, the decisions surrounding each phase can often be undertaken independently of each other. 
All three types of assessments decisions - policy, design and judgement - are significant but, given that they are taken by different people at different times, require different sup- ports. The focus of this project was specifically on assessment design decisions, but under- stood within this broader context. 'Assessment design decisions' can then be defined as the corpus of choices regarding assessment, made by university educators who take responsibility for the module or unit or overall program at a curricular level.

These design decisions are critical to ensure that assessment supports learning. The selection and location of appropriate tasks, feedback processes and other associated features are significant in enabling students to learn (Boud and Molloy 2013), but are often neglected because of a focus on the judgements of work quality or grades (Dijkstra, Van der Vleuten, and Schuwirth 2010). Additionally, Bennett et al.'s 2011 study indicates that Australian university educators have 'significant flexibility and freedom' in how they develop and deliver their units. This suggests that in some contexts at least, supporting educators could lead to real changes in how students experience assessments.

The reality of assessment decisions: how educators design assessments When seeking to understand 'work-as-done', we felt that it was critical to seek views of those university educators, about their assessment design choices and processes. The full details of the empirical study are not discussed here; a more thorough account will be reported elsewhere. Instead, we present here those aspects of the data that informed the development of a resource to support assessment design.

We sought views from educators at four very different Australian universities. One institution was a traditional 'sandstone' university, one was developed in the midtwentieth century but was research intensive, one had originally been an 'institute of technology', and one was a more recent, teaching-focused institution. We sampled from four broad disciplinary groupings; 'pure arts' such as history or languages, 'applied arts' such as edu- cation or journalism, 'pure sciences' such as chemistry or physiology and 'applied sciences' such as engineering or physiotherapy. As the focus was on assessment design, we identified teaching units that had significantly changed assessments in the previous 12 months, either through paperwork review or nomination. We contacted unit/subject coordinators, who were responsible for assessment design and requested interviews. We wanted to understand what might lead educators to innovate in assessment, in particular what prompted them to think beyond 'normal' practice. We wanted to understand the factors that supported or constrained good ideas and their translation, or lack of, into practice. We also wanted to understand how to support educators who are motived to teach 
well as part of their general academic practice, but are perhaps less interested in building particular expertise in assessment.

The initial 10 interviews exposed the thoughtful commitment of the educators to develop meaningful and valuable assessments. There was a wider range of tasks than we anticipated. For example, participants described role-plays (geography), site visits (education), interviews (journalism) and reflections on videotaped practice (physiotherapy), as well as more traditional forms such as exams (biological sciences) and essays (social work). The interviews also highlighted the generally iterative nature of assessment development. Particularly, the data indicated that the foundation of an assessment task was most frequently drawn from a previous task. This included assessments experienced by the educator as a student or implemented at another institution. Most commonly, assessment activities were revised versions of the unit's previous assessment, sometimes with the expectation of further 'tweaking' in the next iteration:

... we didn't like the marking rubric for the blog assignment. So, this year, I changed it ... my lead tutor from last year, from the course, she redesigned it for me.... I tested it [on] the summer term, where I had three students ... . But I didn't like ... some aspects of it. So, for this semester, I merged her marking rubric and my marking rubric and it's much, much better. (Education lecturer)

We also realised that when educators were designing or revising assessments, they did not appear to follow a systematic decision-making process. Interviewees repeatedly described an inspiration followed by an almost complete solution, which then required some tweaking. This did not appear to be a series of considered choices, but more of a creative act:

I wanted to make it practical and real, and connected to education ... but I wanted them to think out of the box ... That's when I had the epiphany of going to these other spaces like [the children's gallery] and inspire them to think out of the box. So, they're not just thinking, 'Well, what's typically in a classroom? How can I really create a very inspiring and engaging educational space?' (Education lecturer)

Lawson (2005) in his summary of the creative process, describes first a formulation of the problem, followed by some early conscious ideas and then by a period without conscious thinking. Finally, there a 'sudden emergence of idea' (Lawson 2005, 149), which can then be once again worked on consciously. This was most akin to the process interviewees described, although they generally struggled to describe their thinking. These 'epiphanies' underlined the differences between our data-set and the constructs described by the cognitively oriented decision-making literature from other disciplines, such as healthcare and aviation. Our thinking began to shift towards supporting educators to develop contextualised and creative solutions and we 
grappled with how to achieve this beyond the many excellent guidelines or 'how to' approaches, which are already readily available.

Following our initial set of 10 interviews, we decided to include those who were responsible for large compulsory units where assessments tend to be more stable over time. In these further 21 interviews, again across four institutions and a range of disciplines, our rationale was to capture more of the routine decision-making involved in assessment design. This second set of data highlighted the distributed nature of assessment design. The person responsible for designing the assessment prior to semester was rarely the person who developed the original paperwork for the unit to be approved. Design was conducted by many individuals, usually with the unit coordinator having primary responsibility, sometimes simultaneously in teams, sometimes sequentially over years:

When I first took this unit over ... I did make some changes [to the assessment]. They had more pracs, they had some oral presentations.... I added a prac and I removed a prac based on how relevant I felt the pracs were and how well aligned with the lecture content they were .... I changed the format of the exam slightly ... there was a bit of a gap there. (Science lecturer)

The influence of the overarching course or program was notable; it was harder to change assessment in core units when many other units depended upon them. There appeared to be a real difference in the capacity to change assessments in different situations. The educator leading a decades-old foundational unit could make marginal and incremental changes, while theeducatorinstigating an elective unitfor the firsttime had more freedom to innovate.

Educators described the impact of the departmental culture on their assessment practice, particularly the influence of the Head of Department. The latter could promote or discourage innovative assessment design, despite having no apparent immediate responsibility for particular units. In general, however, the data, which were from a broad range of institutions and course types, supported Bennett et al.'s (2011) contention that Australian educators have considerable control over assessment design.

As has been noted elsewhere, the influence of the unit's disciplinary traditions (such as an established custom of essays or exams) on the assessment design was pervasive (Meyer et al.2010). What was most striking was that the educators themselves were often unaware of this. For example, in the following quotes interviewees consider the possibility of not including an exam:

Well I suppose, yeah, I suppose ... Well, I don't know actually. It depends whether it's important to test whether they have any basic knowledge, I don't know. I feel uncomfortable not having exams. (Science lecturer) 
I don't think that probably crossed our mind, not having an exam. (Science lecturer)

This indicated that the data, while illuminating, were also limited. It illustrated what practice was, not what it might be, because the educators themselves did not have the broader context, or sometimes expertise, to see beyond their immediate circle of circumstance. For example, some participants were more concerned with standards or plagiarism at a micro level than focusing on learning with a particular form of assessment. The data were additionally limited due to its scope; care must be taken not to overgeneralise from a set of interviews in an Australian context to other contexts in which an educator's opportunities for decision-making may be more constrained.

In order to develop supports for good assessment practice, we needed provide a more comprehensive view. In particular, many of the theorists and researchers already mentioned in this paper (e.g. Nicol and Macfarlane-Dick 2006; Dijkstra, Van der Vleuten, and Schuwirth 2010; Price et al.2011; Boud and Molloy 2013) informed how we developed the Framework. At the same time, we wished to take into account the real priorities and challenges faced by university educators in local contexts.

\section{Learning centred but educator focused: the Assessment Design Decisions Framework}

While the interview data provided key insights into the complex and 'messy' world of localised assessment practice, the literature provided the conceptual and empirical foundations for learning-centred assessment. A framework that supports assessment design should draw from both of these, and therefore both advocate for learning as well as support the educator. As we began to conceptualise the Framework, our conception of the term 'decision' became more nuanced. The term 'decision' rightly acknowledges educators' capacities to make choices about assessment. On the other hand, a 'design decision' is not 'decision-making' as other industries such as aviation and healthcare might characterise it. The interview data clearly indicated that the assessment design process is less reductive and more holistic than other forms of decision-making. In other words, there is no suggestion that assessment can be developed through selecting branches of a decision tree that lead to an optimal outcome.

Our approach asks educators to reflect on a range of 'assessment considerations' that underpin the designs available within the constraints of their own environment. These considerations present some of the necessary tensions within assessment design without providing easy answers. This is intended to promote 'assessment thinking' rather than present a checklist of idealised solutions. If the educator wishes for 
further information regarding the 'how to' of assessment for tertiary education, the resource provides links to the many available publications. The Framework is intentionally agentic, reflecting our aim to provide the educator with a way of analysing the choices available to them that creates meaningfuldesign responses within their own environments. If considerations are not relevant or out of the educator's control, then the educator does not have to engage with them.

The Assessment Design Decisions Framework comprises six categories of assessment considerations, which together present a learning-centred approach to assessment design. While none of these would be at all surprising to those immersed in the assessment literature, it is the ways in which they are represented in terms of the focus on impact on learners and it relation to the academic context, which provides a new contribution. The graphical representation is a circle, which indicates that no category has primacy, and that educators may wish to consider various elements independently of each other. The categories are outlined below.

- Purposes of assessment: This category explores the educators' possible intentions in designing assessment and draws from Boud's (2000) work on sustainable assessment, which focuses on assessment that drives learning and enhances students' future capacities to make judgements.

- Contexts of assessment: This category is derived from the interview data and represents the various and sometimes competing environmental and personal factors which can influence assessment design.

- Learner outcomes: This category brings together the literature and understandings from the interview data to assist the educator in integrating assessment with various documented or unwritten learner outcomes.

- Tasks: This category serves to link the educator to the types of considerations which can help navigate the available assessment literature as the choice and selection of assessment tasks is critical.

- Feedback processes: This category is drawn from contemporary views of feedback, as discussed by Boud and Molloy (2013), which place feedback as a necessary and iterative part of learning through assessment.

- Interactions: This category is primarily derived from the interview data and orients the educator to the types of interactions which will optimise the benefit of good assessment design across units and programs. Educators can overtly consider how to connect with learners and colleagues as a necessary part of their assessment practices.

Box 1 provides a summary of the Framework. 
Box 1. The Assessment Design Decisions Framework (Bearman et al. 2014a). Permission to reproduce this figure is granted under a Creative Commons license.

\section{Assessment Design Decisions Framework}

This Framework helps university teachers make good decisions about assessment design. The six categories draw from existing evidence on good assessment and data from a study of Australian university assessment practices. The Framework identifies the key considerations in assessment design, including the effects of assessment on learning.

\section{Purposes of assessment}

How can assessment: (1) support student learning; (2) generate grades that will form part of subsequent certification; and (3) equip learners for making future judgements?

\section{Contexts of assessment}

Which of the following attributes needs to be considered in assessment design? What specifically about each can be taken into account? How can tensions between different needs be reconciled?

- Characteristics of learners/students

- Institutional assessment principles and policies

- Professional, vocational or employment-related requirements

- Departmental, disciplinary and personal norms, expectations and ideas

- The overall program and the role of the unit/module

- Learning environment, for example, mode (online/face-to-face/blended); class size

\section{Learner outcomes}

How does assessment align with, and promote, desired learner outcomes, including: (1) unit/module learning outcomes; (2) overall program learning outcomes; (3) professional requirements; and (4) learners' general professional or intellectual development.

\section{Tasks}

Learners need to engage with a range of tasks, to (1) develop and (2) demonstrate their learning.

- What is the rationale for each task?

- How do the tasks drive learning? What do the tasks specifically require learners to do?

' How will successful completion be judged?

- How are tasks best distributed across the semester?

- How will students contribute?

- Which tasks will be graded?

\section{Feedback processes}

- How are multiple feedback opportunities achieved through the distribution and relationship of tasks across the unit/module/overall program?

- What types of feedback information will be provided and by whom?

- How will learner performance be used to influence the (re)design of later tasks?

\section{Interactions}

- How will resistance or engagement from learners or colleagues influence assessment processes?

- How will learners understand what is required in the assessment task(s)?

- What information will be needed to improve this assessment for subsequent occasions?

- What associated changes in teaching and learning activities will be required?

The Assessment Design Decisions Framework can be accessed at http://www.asssessmentdecisions.org 
A website was developed as a resource directly available for educators. The associated web guide to the Framework (Bearman et al. 2014b) provides expansions for each consideration, with illustrative quotes from educators and links to resources. The Framework was reviewed by a reference group and potential users, and an independent evaluator concluded that the: 'project has been successful in producing quality outputs, as judged by experts and the target user cohort of academics' (Dawson et al. 2014).

\section{Reflections on the Assessment Design Decisions Framework}

The process of developing the framework led to some interesting observations about how educators develop assessment in higher education and how to support them. First, in general, we were heartened by the thinking that we encountered about assessment. It was creative and considered. There were diverse examples of innovation and, even with very traditional forms like essays, many of our participants gave deep consideration to making the task interesting and meaningful for students. This may be a consequence of our sample; some invitations were not accepted and it could be that these were less confident and/or committed educators. Our initial focus on 'new units' may also have biased the sample to include more innovative academics. However, the majority of our sample would not regard themselves as expert educators or identify themselves as innovative.

The interview data suggested that educators were highly motivated but working in complex, often overwhelming, environments. As we finalised the framework, it was apparent that an individual acting alone cannot change institutional and departmental cultures, but developing innovative assessments within constraints can be satisfying and, for some, fun. We hope our colleagues will be encouraged to draw from their existing creativity and motivation to achieve richer choices for themselves and students.

It is also appropriate to reflect on the limitations of the Framework. It may be less relevant to those settings where control over the assessment does not rest with an individual or a small team. Full evaluation was outside the scope of the project and so current evaluation data are limited. We do not currently have a sense of how the academics interact with this resource in situ. A key research opportunity lies in evaluating whether the Framework fulfils its aims of supporting assessment practice across various disciplinary and national contexts. This research may yield insight both into the strengths and weaknesses of the Framework in specific, and also, the potential for any such resource to develop academic practice. Finally, further study may confirm or refute our insights into how educators make choices about their assessment designs. 


\section{Reflections on assessment design processes}

The process of developing the framework fundamentally changed the way we thought about assessment 'work-as-done'. Similar to others (Macdonald and Joughin 2009; Meyer et al.2010; Price et al.2011), we have identified contextual, institutional or individual tensions which come into play when considering assessment. At the conclusion of developing a resource, which has required us to thinking deeply about how to support 'front-line' educators, we suggest that supporting assessment practice may be about providing means to reconcile different ways of thinking. These notions may be sometimes conflicting or oppositional, but at other times, they are easily aligned.

\section{PROPOSITION 1: Benefit the learner but support the educator}

A learning focus provides a firm basis for the development of assessment practice; however, any form of practice development must take into account the educators' individual circumstances. Good assessment practice often leads to good assessment, but it is not a linear or assured outcome.

\section{PROPOSITION 2: Design is individual but also distributed}

Assessment design does not solely rest in the hands of an individual at a specific point in time; it is mediated by individuals but distributed in nature. Individuals at any instance look forward and backward in time, as well as in consideration of other requirements and in negotiation with a range of colleagues.

\section{PROPOSITION 3: Holistic design processes blend with strategic decisions}

The process of assessment design often appears to be holistic, creative and in some ways spontaneous. On the other hand, educators must make strategic choices about how to successfully develop assessments within the constraints of their particular circumstances.

\section{PROPOSITION 4: Think conceptually, relationally and pragmatically}

Improving assessment practices requires reconciling issues from different levels of consideration: conceptual, interpersonal and pragmatic. Good assessment practices require clarity of focus and an ability to negotiate with others. Recognising the influence of local leaders may help in this process. 
Assessment as implemented is highly contextualised and influenced by local, disciplinary and institutional cultures. These must be reconciled with the need to transcend these influences in order to innovate. Engagement beyond the local environment is required for this as being 'inside' a culture can often preclude seeing alternative perspectives. Inviting an external perspective on assessment practices through formal or informal peer review may provide necessary insights.

\section{Conclusion}

The process of developing the Assessment Design Decisions Framework presents various conceptions which assist in understanding how educators think about assessment design. We propose that educators reconcile, align or mitigate some of the factors which influence assessment design in their own circumstances. Educators can use the Assessment Design Decisions Framework to identify the choices they can make in designing assessment, with particular consideration of the nuances of their personal, departmental, disciplinary and institutional environments.

\section{Acknowledgements}

Sincere thanks to Associate Professor Gordon Joughin for his thoughts on drafts of this manuscript. Support for this publication has been provided by the Australian Government Office for Learning and Teaching. The views in this publication do not necessarily reflect the views of the Australian Government Office for Learning and Teaching.

\section{Disclosure statement}

No potential conflict of interest was reported by the authors.

\section{Funding}

This work was supported by the Office of Learning and Teaching [ID12-2254].

\section{References}

Bailey, Richard, and Mark Garner. 2010. "Is the Feedback in Higher Education Assessment Worth the Paper it is Written on? Teachers' Reflections on Their Practices." Teaching in Higher Education 15 (2): 187-198.

Bearman, Margaret, Phillip Dawson, David Boud, Matt Hall, Sue Bennett, Elizabeth Molloy, and Gordon Joughin. 2014a. "Assessment Design Decisions Framework.” Accessed October 9. http://www.assessmentdecisions.org/framework/. 
Bearman, Margaret, Phillip Dawson, David Boud, Matt Hall, Sue Bennett, Elizabeth Molloy, and Gordon Joughin. 2014b. "Guide to the Assessment Design Decisions Framework." Accessed October 3. http://www.assessmentdecisions.org/guide/.

Bennett, Sue, Lisa Thomas, Shirley Agostinho, Lori Lockyer, Jennifer Jones, and Barry Harper. 2011. "Understanding the Design Context for Australian University Teachers: Implications for the Future of Learning Design." Learning, Media and Technology 36 (2): 151-167.

Borko, Hilda, Sarah A. Roberts, Richard Shavelson, Philip Clarkson, and Norma Presmeg. 2008. "Teachers' Decision Making: from Alan J. Bishop to Today Critical Issues in Mathematics Education." In Critical Issues in Mathematics Education: Major Contributions of Alan Bishop, edited by Philip Clarkson and Norma Presmeg, 37-67. New York: Springer.

Boud, David. 2000. "Sustainable Assessment: Rethinking Assessment for the Learning Society."

Studies in Continuing Education 22 (2): 151-167.

Boud, David, and Associates. 2010. Assessment 2020: Seven Propositions for Assessment Reform in Higher Education. Sydney: Australian Learning and Teaching Council.

Boud, David, and Elizabeth Molloy. 2013. "Rethinking Models of Feedback for Learning: The Challenge of Design." Assessment \& Evaluation in Higher Education 38 (6): 698-712.

Braithwaite, Jeffrey, Robert L. Wears, and Erik Hollnagel. 2015. "Resilient Health Care: Turning Patient Safety on its Head." International Journalfor Quality in Health Care 27 (5): 418-420.

Croskerry, Pat. 2005. "The Theory and Practice of Clinical Decision-Making." Canadian Journal of Anesthesia/Journal canadien d'anesthésie 52 (1): R1-R8.

Dawson, Phillip, Margaret Bearman, Elizabeth Molloy, David Boud, Gordon Joughin, and Sue Bennett. 2014. "Improving Assessment: Understanding Educational Decision-Making in Practice." Final report to the Office for Learning \& Teaching. http://www.olt.gov.au/project- improving-assessmentunderstanding-educational-decision-making-practice-2012

Dijkstra, J., C. P. M. Van der Vleuten, and L. W. T. Schuwirth. 2010. "A New Framework for Designing Programmes of Assessment." Advances in Health Sciences Education 15 (3): 379-393.

Eley, Malcolm. 2006. "Teachers' Conceptions of Teaching, and the Making of Specific Decisions in Planning to Teach." Higher Education 51 (2): 191214.

Falchikov, Nancy. 2013. Improving Assessment Through Student Involvement: Practical Solutions for Aiding Learning in Higher and Further Education. London: Routledge.

Fletcher, Richard B., Luanna H. Meyer, Helen Anderson, Patricia Johnston, and Malcolm Rees. 2012. "Faculty and Students Conceptions of Assessment in Higher Education." Higher Education 64 (1): 119-133. 
Gibbs, Graham, and Harriet Dunbar-Goddet. 2007. The Effects of Programme Assessment Environments on Student Learning. York: Higher Education Academy.

Gore, Jennifer, James Ladwig, Wendy Elsworth, and Hywel Ellis. 2009. Quality Assessment Framework: A Guide for Assessment Practice in Higher Education. Sydney: Australian Teaching and Learning Council.

Lawson, Bryan. 2005. How Designers Think: The Design Process Demystified. 5th ed. Oxford: Architectural Press.

Macdonald, Ranald, and Gordon Joughin. 2009. "Changing Assessment in Higher Education: A Model in Support of Institution-Wide Improvement." In Assessment, Learning and Judgement in Higher Education, edited by Gordon Joughin, 1-21.Dordrecht: Springer.

Meyer, Luanna H., Susan Davidson, Lynanne McKenzie, Malcolm Rees, Helen Anderson, Richard Fletcher, and Patricia M. Johnston. 2010. "An Investigation of Tertiary Assessment Policy and Practice: Alignment and Contradictions." Higher Education Quarterly 64 (3): 331-350.

Nicol, David J. 2010. "From Monologue to Dialogue: Improving Written Feedback Processes in Mass Higher Education.” Assessment \& Evaluation in Higher Education 35 (5): 501-517.

Nicol, David J, and Debra Macfarlane-Dick. 2006. "Formative Assessment and Self-Regulated Learning: A Model and Seven Principles of Good Feedback Practice." Studies in Higher Education 31 (2): 199-218.

Norton, Lin, Bill Norton, and Lee Shannon. 2013. "Revitalising Assessment Design: What is Holding New Lecturers Back?" Higher Education 66 (2): 233-251.

Offerdahl, Erika G., and Debra Tomanek. 2011. "Changes in Instructors' Assessment Thinking Related to Experimentation with New Strategies." Assessment \& Evaluation in Higher Education 36 (7): 781-795.

Plant, Katherine L., and Neville A. Stanton. 2013. "What is on Your Mind? Using the Perceptual Cycle Model and Critical Decision Method to Understand the Decision-Making Process in the Cockpit." Ergonomics 56 (8): 1232-1250.

Price, Margaret, Jude Carroll, Berry O'Donovan, and Chris Rust. 2011. "If I Was Going There I Wouldn't Start from Here: A Critical Commentary on Current Assessment Practice." Assessment \& Evaluation in Higher Education 36 (4): 479-492.

Shipman, Debra, Michelle Roa, Jack Hooten, and Zhan Jenny Wang. 2012. "Using the Analytic Rubric as an Evaluation Tool in Nursing Education: The Positive and the Negative." Nurse Education Today 32 (3): 246-249.

Van der Vleuten, C. P. M., L. W. T. Schuwirth, E. W. Driessen, J. Dijkstra, D. Tigelaar, L. K. J. Baartman, and J. Van Tartwijk. 2012. "A Model for Programmatic Assessment Fit for Purpose.” Medical Teacher 34 (3): 20514. 